\title{
Color changes of esthetic elastomeric ligatures evaluated with the Commission Internationale d'Éclairage color system
}

\author{
Vanessa Dias da Silva ${ }^{1}$, Caroline Dias ${ }^{2}$, Leandro Berni Osório ${ }^{3}$, Paulo Ricardo Baccarin \\ Matje $^{1}$, Luciane Macedo de Menezes ${ }^{1}$, Eduardo Martinelli Santayana de Lima ${ }^{1}$
}

Correspondence: Dr. Eduardo Martinelli Santayana

de Lima

Email: elima@pucrs.br

\author{
'School of Health Sciences, Pontifical Catholic \\ University of Rio Grande Do Sul, Porto Alegre, RS, \\ Brazil, \\ 2Private practice, Cachoeirinha, RS, Brazi, \\ ${ }^{3}$ Department of Stomatology, School of Dentistry, \\ Federal University of Santa Maria, Santa Maria, RS, \\ Brazil
}

\section{ABSTRACT}

Objective: The aim of this study was to assess and compare color changes in esthetic elastomeric ligatures after 30 days in situ using a spectrophotometer and the Commission Internationale d'Éclairage (CIE) color system. Materials and Methods: The sample comprised elastomeric ligatures of four color groups $(n=42)$ : blue pearl (BP); colorless; white pearl (WP); and pearl. Four samples from each group were allocated in for quadrants of seven patients in a split-mouth model. Color measurements were performed with a spectrophotometer in the elastomeric ligatures as received (T0) and after 30 days in situ (T1). Variables $\mathrm{L}^{*}, \mathrm{a}^{*}$, and $\mathrm{b}^{*}$ were compared between times $(\mathrm{T} 1-\mathrm{T} 0)$ with Wilcoxon paired ranks; color changes were compared between groups with Kruskal-Wallis test; Dunn's test was used for multiple comparisons. Spearman's correlation was applied between CIELAB and CIEDE2000 calculations. Results: All groups showed color changes (T1-T0) in a* and b*, but only the Group $\mathrm{BP}$ had a change in $\mathrm{L}^{*}(P<0.01)$. Group $\mathrm{C}$ showed the greatest lightness decrease $(\Delta \mathrm{L}=-2.49 \pm 0.47)(P<0.05)$, the smallest yellowing $(\Delta \mathrm{b}=3.17 \pm 0.88)(P<0.05)$, and the smallest total color change $\left(\Delta \mathrm{E}_{2000}=3.19 \pm 0.85\right)$, which had no statistical difference from Group WP $\left(\Delta \mathrm{E}_{2000}=3.36 \pm 0.53\right)$. Correlation between $\Delta \mathrm{E}_{\text {ab }}$ and $\Delta \mathrm{E}_{2000}$ was moderate $(r=0.59 ; P<0.01)$. Conclusions: Esthetic elastomeric ligatures became yellowish after 30 days in situ, and there were color differences between them.

Key words: Elastomeric ligatures, esthetics, orthodontic appliances, pigmentation

\section{INTRODUCTION}

Esthetic orthodontic appliances are a primary demand of adult patients. Due to this, the dental industry has been engaged in the development of more esthetic and less visible appliances. Polycarbonate brackets and polycrystalline/monocrystalline ceramic brackets have improved the esthetics

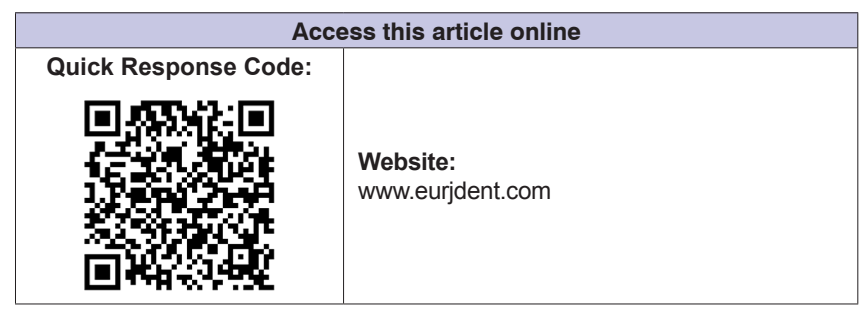

preserving the biomechanical features of the fixed appliances. Clear elastomeric ligatures complete a translucent look. ${ }^{[1-3]}$ However, the orthodontic esthetic set fails when the elastomeric ligatures

This is an open access journal, and articles are distributed under the terms of the Creative Commons Attribution-NonCommercial-ShareAlike 4.0 License, which allows others to remix, tweak, and build upon the work non-commercially, as long as appropriate credit is given and the new creations are licensed under the identical terms.

For reprints contact: reprints@medknow.com

How to cite this article: da Silva VD, Dias C, Osório LB, Baccarin Matje PR, de Menezes LM, Santayana de Lima EM. Color changes of esthetic elastomeric ligatures evaluated with the Commission Internationale d'Éclairage color system. Eur J Dent 2018;12:428-33.

DOI: 10.4103/ejd.ejd_355_17 
stain due to dyes in the diet and conditions of the oral environment. ${ }^{[3-9]}$

Visual color perception results from physiological and psychological responses to the wavelengths of light stimulation on cell receptors of the human eye. ${ }^{[10]}$ In dentistry, color determinations are routinely performed using visual matching to the VITA shade guide. ${ }^{[11,12]}$ However, the use of a spectrophotometer on color evaluation eliminates the influence of viewing conditions, observer's experience, and eye fatigue. Color assessments are more predictable and reliable using a spectrophotometer than the shade guide. ${ }^{[13,14]}$ The spectrophotometer identifies light wavelengths as numerical values in three coordinates (lightness, green-red, and blue-yellow) resembling the human eye visual system. ${ }^{[15]}$ Color calculation derives from mathematical formulas defined by the International Commission Internationale d'Éclairage (CIE). Original CIELAB formula evolved to CIEDE2000 color-difference equation with lightness, chroma, and hue weighting functions improving the performance for blue and gray colors. Currently, CIEDE2000 is the best color evaluation method in dentistry. ${ }^{[16-21]}$

Only in vitro studies used spectrophotometers and the CIE color system to quantify staining of elastomeric ligatures. Clinical studies assessed pigmentation by means of qualitative scores. Until now, no in situ studies evaluated the color changes of esthetic elastomeric ligatures using a spectrophotometer. CIELAB and CIEDE2000 equations could distinguish color changes in three coordinates, elucidating the problem of elastomeric ligature pigmentation during the interval between consultations. Therefore, the aim

\begin{tabular}{|c|c|c|c|}
\hline Group & $n$ & Color & Manufacturer \\
\hline $\mathrm{BP}$ & 42 & Blue pearl & Ortho Technology, Tampa, FL, USA \\
\hline C & 42 & Colorless & $\begin{array}{l}\text { American Orthodontics, } \\
\text { Sheboygan, WI, USA }\end{array}$ \\
\hline WP & 42 & White pearl & American Orthodontics \\
\hline $\mathrm{P}$ & 42 & Pearl & Ortho Technology \\
\hline
\end{tabular}

of this study was to assess and compare in situ color changes of different esthetic elastomeric ligatures using a spectrophotometer and the CIE color system. The null hypothesis was that there is no color difference related to the oral exposure and to the elastomeric ligatures types. The alternative hypothesis was that there are color differences in the three coordinates in all elastomeric ligatures types.

\section{MATERIALS AND METHODS}

The Ethics Committee of the Pontifical Catholic University approved this in situ study. The subjects' rights were preserved, and an informed consent was obtained from all participants. Esthetic elastomeric ligatures of two dental companies were allocated in four color groups $(n=42)$ [Table 1]. Four elastomeric ligatures from each group were randomly allocated in four quadrants of seven patients in a split-mouth model. Sample size calculation indicated the need of 33 elastomeric ligatures per group to detect a bilateral difference of 0.5 units in the total color change $\left(\Delta \mathrm{E}_{\mathrm{ab}}\right)$, with a power of $80 \%$ and significance level of 5\% (Statistical Solutions, LLC Systems, Cottage Grove, WI, USA). The sample of 42 elastomeric ligatures per group considered $25 \%$ follow-up loss. The eligibility criteria for participation in the study were adult patients undergoing orthodontic treatment with fixed appliances, in good general and oral health conditions, with no congenital malformations and presenting at least four teeth per hemiarch both in the maxilla and in the mandible. Seven patients (three males, four females; mean age: 35.5 years) from a private orthodontic clinic met criteria and signed an informed consent form agreeing with their participation in the study.

The esthetic elastomeric ligatures were placed in ceramic brackets (Radiance, American Orthodontics) with the aid of a Mathieu plier, avoiding overstretching. Patients were instructed on proper oral hygiene using dental floss, toothbrush, and dye-free toothpaste. No recommendation was made regarding the daily diet. The next consultations were scheduled after a 30-day

\begin{tabular}{|c|c|c|c|c|c|c|c|}
\hline \multirow[t]{2}{*}{ Group } & \multirow[t]{2}{*}{$n$} & \multicolumn{2}{|c|}{$\mathbf{L}^{*}$} & \multicolumn{2}{|c|}{$a^{*}$} & \multicolumn{2}{|c|}{$\mathbf{b}^{*}$} \\
\hline & & Mean $\pm S D$ & $P$ & Mean \pm SD & $P$ & Mean \pm SD & $P$ \\
\hline $\mathrm{BP}$ & 41 & $-1.96 \pm 0.59$ & $0.01^{*}$ & $0.58 \pm 0.39$ & $<0.001^{*}$ & $4.52 \pm 0.61$ & $<0.001^{*}$ \\
\hline$C$ & 34 & $-2.49 \pm 0.47$ & 0.94 & $0.72 \pm 0.61$ & $<0.001^{*}$ & $3.17 \pm 0.88$ & $<0.001^{*}$ \\
\hline WP & 36 & $-2.08 \pm 0.52$ & 0.28 & $0.50 \pm 0.43$ & $<0.001^{*}$ & $3.76 \pm 0.66$ & $<0.001^{*}$ \\
\hline$P$ & 34 & $-1.93 \pm 0.66$ & 0.87 & $0.83 \pm 0.45$ & $<0.001^{*}$ & $4.08 \pm 1.1$ & $<0.001^{*}$ \\
\hline
\end{tabular}

Wilcoxon test (T1-T0), * indicates statistical significance; L*, lightness; a*, green-red chromaticity; b*, blue-yellow chromaticity; and SD, standard deviation 
interval when patients underwent to professional toothbrushing. Duplicated samples of elastomeric ligatures were removed using a dental probe and stored in sealed 96-well microplates, to protection against heat, light, and moisture until to color evaluation within $24 \mathrm{~h}$.

\section{Color measurements}

Quantitative and qualitative color assessments were carried out in the elastomeric ligatures as received (T0) and after 30 days in situ (T1). Color measurements were carried out using a portable spectrophotometer (SP60 X-Rite, Grand Rapids, MI, USA) in white background, under the same lighting, in a blind random sequence [Figure 1]. The spectrophotometer recorded numeric values in the coordinates $L^{*}, a^{*}$, and $b^{*}$ according to the CIE color system. Coordinate $\mathrm{L}^{*}$ determines a lightness level from 0 (completely

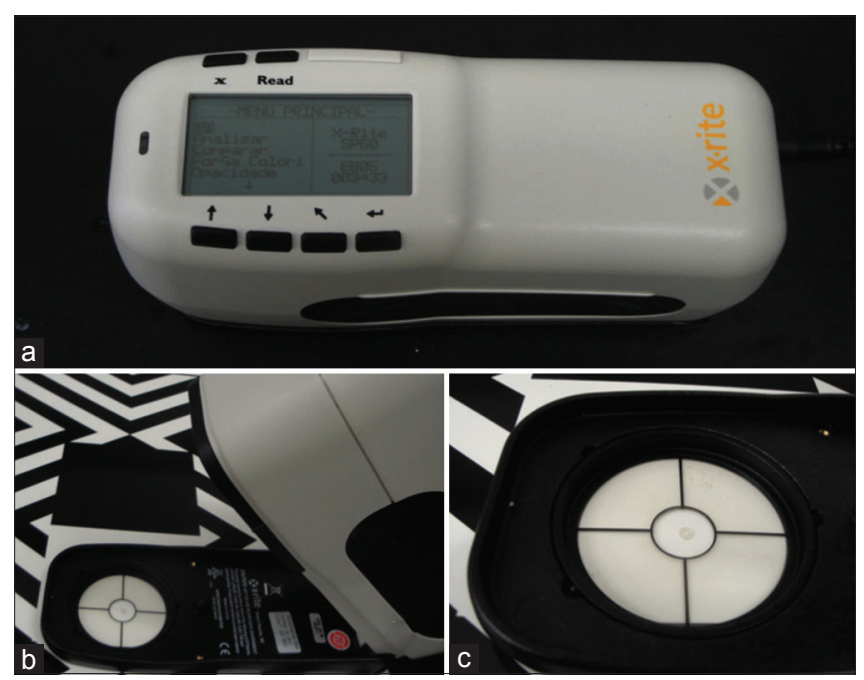

Figure 1: (a) Portable spectrophotometer (SP60 X-Rite, Grand Rapids, MI, USA); (b) Selection of a white background; (c) A sample of elastomeric ligature placed for color assessment black) to 100 (pure white). Coordinate a* identifies chromaticity in the green-red axis, where positive values indicate red color and negative values mean a green shade. Coordinate $b^{*}$ defines chromaticity in the blue-yellow axis, where yellow is positive and blue is negative. ${ }^{[14,15]}$ Differences in $\mathrm{L}^{*}, \mathrm{a}^{*}$, and $b^{*}$ measures between the evaluation times (T1-T0) in each group (blue pearl [BP], colorless, white pearl $[\mathrm{WP}]$, and pearl) indicated a color variation in three coordinates $(\Delta \mathrm{L}, \Delta \mathrm{a}$, and $\Delta \mathrm{b})$. Calculation of total color change of esthetic elastomeric ligatures was performed using the CIELAB $\left(\Delta \mathrm{E}_{\mathrm{ab}}\right)$ and the CIEDE2000 $\left(\Delta \mathrm{E}_{2000}\right)$ equations. ${ }^{[16]}$ Reproducibility testing was carried out on repeated measures taken by one observer in 20 samples that were randomly selected, after a 7-day interval. Visual evaluations of color were performed in a $1366 \times 768$ pixel screen, which displayed samples from the four elastomeric ligatures groups as received (T0) and after 30 days in situ (T1) [Figure 2]. Twelve observers (four orthodontists, four graduate orthodontic students, and four undergraduate students) ranked the elastomeric ligature groups in a one to four sequence, where the smallest color change was the rank one and the greatest color change was rank four.

\section{Statistical analysis}

Data were analyzed with SPSS 20.0 software (IBM, Armonk, NY, USA). Intraobserver reproducibility was tested with intraclass correlation coefficient (ICC). The Shapiro-Wilk test attested that the data were not normally distributed for all dependent variables $\left(\mathrm{L}^{*}, \mathrm{a}^{*}, \mathrm{~b}^{*}, \Delta \mathrm{L}, \Delta \mathrm{a}, \Delta \mathrm{b}, \Delta \mathrm{E}_{\mathrm{ab}}\right.$, and $\left.\Delta \mathrm{E}_{2000}\right)$. Variables $\mathrm{L}^{*}$, $\mathrm{a}^{*}$, and $\mathrm{b}^{*}$ were compared between times (T1-T0) with Wilcoxon paired ranks; color changes $\left(\Delta \mathrm{L}, \Delta \mathrm{a}, \Delta \mathrm{b}, \Delta \mathrm{E}_{\mathrm{ab}}\right.$ and $\Delta \mathrm{E}_{2000}$ ) were compared between groups (BP, C, WP,
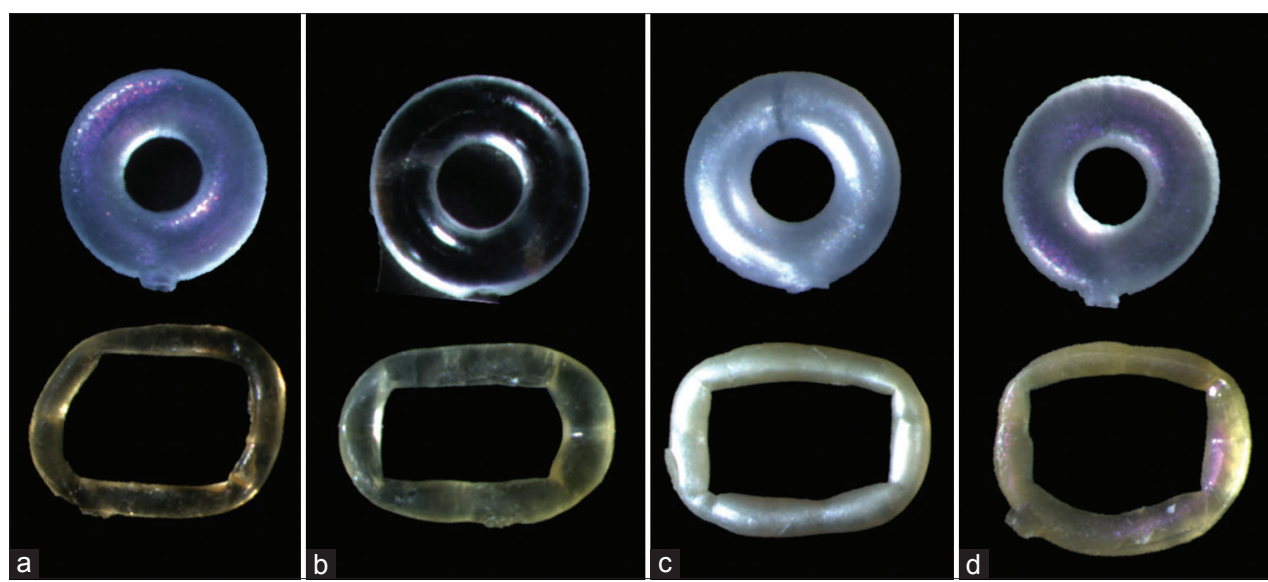

Figure 2: Esthetic elastomeric ligatures as received from the manufacturer and after 30 days in situ. (a) Group BP, blue pearl; (b) Group C, colorless; (c) Group WP, white pearl; and (d) Group P, pearl 
and P) with the Kruskal-Wallis test; Dunn's test was used for multiple comparisons. Spearman's correlation was applied between CIELAB and CIEDE2000 calculations. Visual ranks of color changes were analyzed through Kendall's coefficient. Results were significant at the 95\%confidence level $(P<0.05)$.

\section{RESULTS}

Twenty-three samples were lost throughout the study (14\%); intraclass coefficient showed excellent agreement between repeated measures of $L^{*}, a^{*}$, and $b^{*}(I C C=0.99)$. Under naked eye, all groups of esthetic elastomeric ligatures underwent pigmentation after 30 days in situ [Figure 2].

Table 2 reveals that all groups of elastomeric ligatures showed statistically significant chromaticity change both in the green-red axis $\left(\mathrm{a}^{*}\right)$ and in the blue-yellow axis $\left(b^{*}\right)(P<0.001)$. Only the Group BP presented a change in lightness level $\left(\mathrm{L}^{*}\right)$ with statistical significance $(P=0.01)$. In all groups, mean changes were negative for $L^{*}(-1.93$ to -2.49$)$, slightly positive for $\mathrm{a}^{*}(0.50-0.83)$, and positive for $\mathrm{b}^{*}(3.17-4.52)$.

Table 3 shows the elastomeric ligatures of Group C had the greatest lightness decrease $(\Delta \mathrm{L}=-2.49 \pm 0.47)$ and the smallest yellowing $(\Delta b=3.17 \pm 0.88)(P<0.05)$. Yellowing of elastomeric ligatures from Group BP was statistically greater $(\Delta \mathrm{b}=4.52 \pm 0.61)$ than that of Group WP $(\Delta b=3.76 \pm 0.66)(P<0.05)$. Only red color change of statistical significance was between Groups $P(\Delta \mathrm{b}=0.83 \pm 0.45)$ and WP $(\Delta \mathrm{b}=0.50 \pm 0.43)(P<0.05)$.
Table 4 reveals that the smallest total color change was in the Group $C\left(\Delta \mathrm{E}_{2000}=3.19 \pm 0.85\right)$, which showed statistical difference compared to Groups $P\left(\Delta \mathrm{E}_{2000}=3.74 \pm 0.91\right)$ and $\mathrm{BP}\left(\Delta \mathrm{E}_{2000}=4.11 \pm 0.54\right.$, $P<0.05)$, and no difference compared to Group $\mathrm{WP}\left(\Delta \mathrm{E}_{2000}=3.36 \pm 0.53\right)$. Visual evaluations indicated a smaller color change in the Group WP, followed by Groups $\mathrm{C}, \mathrm{P}$, and BP $(\mathrm{W}=0.903 ; P<0.001)$. Correlation between $\Delta \mathrm{E}_{\mathrm{ab}}$ and $\Delta \mathrm{E}_{2000}$ was moderate $(r=0.59 ; P<0.01)$; only CIEDE2000 detected statistically significant color differences between elastomeric ligature groups.

\section{DISCUSSION}

The null hypothesis was rejected as the esthetic elastomeric ligatures showed color changes after 30 days in situ with statistical difference between elastomeric ligatures types. The alternative hypothesis was partially accepted because all groups presented a statistically significant color change in the coordinates $\mathrm{a}^{*}$ and $\mathrm{b}^{*}$, but only the Group BP presented a significant change in the coordinate $\mathrm{L}^{*}$.

Esthetic elastomeric ligatures remained in situ for 30 days, which is ordinary time interval between consultations during the orthodontic treatment of adults. All tested elastomeric ligatures were made with injection molding to prevent that material intrinsic features could influence color evaluations. ${ }^{[2,5]}$ The spectrophotometer and the CIE color system allowed numeric and accurate color difference evaluations that overcame limited source of information from visual evaluations.

\begin{tabular}{|c|c|c|c|c|c|c|c|c|c|c|}
\hline \multirow[t]{2}{*}{ Group } & \multirow[t]{2}{*}{$n$} & \multicolumn{3}{|c|}{$\Delta \mathbf{L}$} & \multicolumn{3}{|c|}{$\Delta \mathbf{a}$} & \multicolumn{3}{|c|}{$\Delta \mathbf{b}$} \\
\hline & & Mean $\pm S D$ & Minimum & Maximum & Mean $\pm S D$ & Minimum & Maximum & Mean $\pm S D$ & Minimum & Maximum \\
\hline $\mathrm{BP}$ & 41 & $-1.96 \pm 0.59^{A}$ & -3.38 & -0.77 & $0.58 \pm 0.39^{A B}$ & -0.21 & 1.22 & $4.52 \pm 0.61^{\mathrm{C}}$ & 3.19 & 5.83 \\
\hline$C$ & 34 & $-2.49 \pm 0.47^{B}$ & -3.25 & -1.46 & $0.72 \pm 0.61^{\mathrm{AB}}$ & -0.36 & 2.69 & $3.17 \pm 0.88^{A}$ & 1.99 & 4.81 \\
\hline WP & 36 & $-2.08 \pm 0.52^{\mathrm{A}}$ & -3.42 & -1.31 & $0.50 \pm 0.43^{\mathrm{A}}$ & -0.17 & 1.31 & $3.76 \pm 0.66^{\mathrm{B}}$ & 2.17 & 4.98 \\
\hline$P$ & 34 & $-1.93 \pm 0.66^{A}$ & -3.13 & 1.1 & $0.83 \pm 0.45^{B}$ & 0.05 & 1.92 & $4.08 \pm 1.1^{\mathrm{BC}}$ & 0.57 & 6.03 \\
\hline
\end{tabular}

Kruskal-Wallis test $(P<0.05)$ and Dunn's multiple comparisons test. Different letters indicate statistical significance by columns. $\Delta \mathrm{L}$ : Lightness variation, $\Delta \mathrm{a}$ : Variation in the green-red axis, $\triangle \mathrm{b}$ : Variation in the blue-yellow axis, SD: Standard deviation, BP: Blue pearl, C: Colorless, WP: White pearl, P: Pearl

\begin{tabular}{|c|c|c|c|c|c|c|c|c|c|}
\hline \multirow[t]{2}{*}{ Group } & \multirow[t]{2}{*}{$n$} & \multicolumn{3}{|c|}{$\Delta \mathbf{E}_{\mathrm{ab}}$} & \multicolumn{3}{|c|}{$\Delta \mathbf{E}_{2000}$} & \multicolumn{2}{|c|}{ Visual } \\
\hline & & Mean士SD & Minimum & Maximum & Mean士SD & Minimum & Maximum & Mean rank & $w$ \\
\hline $\mathrm{BP}$ & 41 & $5.00 \pm 0.68$ & 3.73 & 6.44 & $4.11 \pm 0.54^{C}$ & 3.00 & 5.22 & 4 & $0.903^{*}$ \\
\hline $\mathrm{C}$ & 34 & $4.15 \pm 0.91$ & 2.62 & 6.37 & $3.19 \pm 0.85^{A}$ & 1.98 & 5.58 & 1.58 & \\
\hline WP & 36 & $4.37 \pm 0.71$ & 3.03 & 5.79 & $3.36 \pm 0.53^{A B}$ & 2.20 & 4.31 & 1.42 & \\
\hline$P$ & 34 & $4.65 \pm 1.11$ & 1.24 & 6.87 & $3.74 \pm 0.91^{\mathrm{BC}}$ & 0.83 & 5.27 & 3 & \\
\hline
\end{tabular}

Kruskal-Wallis test $(P<0.05)$ and Dunn's multiple comparisons test; different letters indicate statistical significance by columns. Kendall's tau coefficient $(W)(P<0.05)$; ${ }^{*}$ Statistical significance, rank 1-4, smaller to greater color change. $\Delta \mathrm{E}_{\mathrm{ab}}$ : CIELAB, $\Delta \mathrm{E}_{2000}$ : CIEDE2000, SD: Standard deviation, BP: Blue pearl, C: Colorless, WP: White pearl, P: Pearl 
Pigmentation on esthetic elastomeric ligatures was evident under naked eye, what is in line with other clinical studies with the same evaluation time. ${ }^{[3,4]}$ Calculations of total color changes using CIELAB and CIEDE2000 equations surpassed the perception threshold of the human eye. A systematic review on color differences in Dentistry found that $\Delta \mathrm{E}_{\mathrm{ab}}$ equal to 1 is perceptible for most observers in $50 \%$ of the times. Thresholds of acceptable $\Delta \mathrm{E}_{\mathrm{ab}}$ varied between 2 and 3.7 units. ${ }^{[22]}$ Another study using the CIEDE2000 equation reported the thresholds of 0.8 for perceptibility and 1.8 for acceptability of total color change. ${ }^{[23]}$ In the current study, total color changes were above $\Delta \mathrm{E}_{\mathrm{ab}} 3.7$ in $83 \%$ of the sample and above two units of $\Delta \mathrm{E}_{2000}$ in $98 \%$. Visual rank of color changes reflected the numeric total color change. In both evaluations, the Groups C and WP showed less total color change, followed by the Groups $P$ and BP.

Decreases in lightness level (negative $\Delta \mathrm{L}$ ) would be perceptible to the human eye whereas red color changes (positive $\Delta \mathrm{a}$ ) would not. On the other hand, color changes to yellow (positive $\Delta b$ ) surpassed the acceptable limits. Studies in vitro already reported that clear elastomeric ligatures are more susceptible to color change in the blue-yellow axis than in the other coordinates of the CIE system. ${ }^{[1,5]}$ In the present study, the elastomeric ligatures from Group C showed both the smallest yellowing and the greatest decrease in lightness. One says that $C$ elastomeric ligatures are not suitable for patients consuming large amounts of coffee, whereas they are adequate for who follows a daily diet with yellow-colored foods. ${ }^{[5]}$ The present study enriches the current knowledge on pigmentation of esthetic elastomeric ligatures by quantifying the color changes in the three coordinates of the CIE system. Raw data analysis revealed that a color change to yellow was responsible for $60 \%-83 \%$ of total color change, while a lightness decrease had an influence between $16 \%$ and $37 \%$. Red color change showed a weight of $<3 \%$ cent in total color change in all elastomeric ligatures groups. Yellowing is a weakness of the esthetic elastomeric ligatures that manufacturers need overcome as soon as possible.

Correlation between CIELAB and CIEDE2000 equations is well established. ${ }^{[24,25]}$ However, material intrinsic features may influence in the equation performance. ${ }^{[18]}$ CIEDE2000 enabled detect statistical significance in small color differences among groups and showed a better performance than CIELAB in color evaluation of elastomeric ligatures. ${ }^{[19,20]}$ Moderate correlation $(r=0.591)$ between CIELAB and CIEDE2000 in the present study reinforces the importance of weighting lightness, chroma, and hue in the calculation of total color change of esthetic elastomeric ligatures.

Because all the esthetic elastomeric ligatures tested in the current study showed color changes above acceptable thresholds, the differences among groups were of limited clinical implication. A predictable pigmentation on esthetic elastomeric ligatures should be emphasized to patients before treatment as a shorter interval between consultations might be necessary to work around the pigmentation problem. The discoloration has been concern of research in dental materials. ${ }^{[26]}$ Further studies on staining of elastomeric ligatures might be helpful on the improvement of these materials. ${ }^{[27]}$

\section{CONCLUSIONS}

All elastomeric ligatures showed color changes after 30 days in situ and became yellowish, overall. Colorless elastomeric ligatures (Group C) showed the smallest yellowing but also the greatest lightness decrease. The total color change was less in the Groups $C$ and WP than in the Groups $P$ and BP.

\section{Financial support and sponsorship}

This study was financially supported by the Coordenação de Aperfeiçoamento de Pessoal de Nível Superior in the form of MSc scholarship.

\section{Conflicts of interest}

There are no conflicts of interest.

\section{REFERENCES}

1. Fernandes AB, Ribeiro AA, Araujo MV, Ruellas AC. Influence of exogenous pigmentation on the optical properties of orthodontic elastic ligatures. J Appl Oral Sci 2012;20:462-6.

2. Kim SH, Lee YK. Measurement of discolouration of orthodontic elastomeric modules with a digital camera. Eur J Orthod 2009;31:556-62.

3. Silva AV, Mattos GV, Kato CM, Normando D. In vivo color changes of esthetic orthodontic ligatures. Dent Press J Orthod 2012;17:76-80.

4. Kawabata E, Dantas VL, Kato CB, Normando D. Color changes of esthetic orthodontic ligatures evaluated by orthodontists and patients: A clinical study. Dental Press J Orthod 2016;21:53-7.

5. Ardeshna AP, Vaidyanathan TK. Colour changes of orthodontic elastomeric module materials exposed to in vitro dietary media. J Orthod 2009;36:177-85.

6. Cavalcante JS, de Castellucci e Barbosa M, Sobral MC. Evaluation of the susceptibility to pigmentation of orthodontic esthetic elastomeric ligatures. Dental Press J Orthod 2013;18:20.e1-8.

7. Fernandes AB, Ruellas AC, Araújo MV, Sant'Anna EF, Elias CN. Assessment of exogenous pigmentation in colourless elastic ligatures. J Orthod 2014;41:147-51

8. Soldati DC, Silva RC, Oliveira AS, Kaizer MR, Moraes RR. Color stability of five orthodontic clear elastic ligatures. Orthodontics (Chic.) 2013;14:e60-5.

9. Dias da Silva V, de Lima EM, Dias C, Osório LB. Analysis of the 
influence of food colorings in esthetic orthodontic elastomeric ligatures. Open Dent J 2016;10:516-21.

10. Berns RS, Billmeyer FW, Saltzman M, Billmeyer FW. Billmeyer and Saltzman's Principles of Color Technology. $3^{\text {rd }}$ ed. New York: Wiley; 2000.

11. Hammad IA. Intrarater repeatability of shade selections with two shade guides. J Prosthet Dent 2003;89:50-3.

12. Elamin $\mathrm{HO}$, Abubakr NH, Ibrahim YE. Identifying the tooth shade in group of patients using vita easyshade. Eur J Dent 2015;9:213-7.

13. Gómez-Polo C, Gómez-Polo M, Celemin-Viñuela A, Martínez Vázquez De Parga JA. Differences between the human eye and the spectrophotometer in the shade matching of tooth colour. J Dent 2014;42:742-5.

14. Johnston WM. Color measurement in dentistry. J Dent 2009;37 Suppl 1:e2-6.

15. Hunter Lab. Hunter lab color scale. Insight Color 2008;8:1-4.

16. Sharma G, Wu W, Dalal EN. The CIEDE2000 color-difference formula: Implementation notes, supplementary test data, and mathematical observations. Color Res Appl 2005;30:21-30.

17. Luo MR, Cui G, Rigg B. The development of the CIE2000 colour-difference formula: CIEDE2000. Color Res Appl 2001;26:340-50.

18. Pérez Mdel M, Saleh A, Yebra A, Pulgar R. Study of the variation between CIELAB delta $E^{*}$ and CIEDE2000 color-differences of resin composites. Dent Mater J 2007;26:21-8.

19. Gómez-Polo C, Portillo Muñoz M, Lorenzo Luengo MC, Vicente P, Galindo P, Martín Casado AM, et al. Comparison of the CIELab and CIEDE2000 color difference formulas. J Prosthet Dent 2016;115:65-70.
20. Pecho OE, Ghinea R, Alessandretti R, Pérez MM, Della Bona A. Visual and instrumental shade matching using CIELAB and CIEDE2000 color difference formulas. Dent Mater 2016;32:82-92.

21. Perez Mdel M, Ghinea R, Herrera LJ, Ionescu AM, Pomares H, Pulgar R, et al. Dental ceramics: A CIEDE2000 acceptability thresholds for lightness, chroma and hue differences. J Dent 2011;39 Suppl 3:e37-44.

22. Khashayar G, Bain PA, Salari S, Dozic A, Kleverlaan CJ, Feilzer AJ, et al. Perceptibility and acceptability thresholds for colour differences in dentistry. J Dent 2014;42:637-44.

23. Paravina RD, Ghinea R, Herrera LJ, Bona AD, Igiel C, Linninger M, et al. Color difference thresholds in dentistry. J Esthet Restor Dent 2015;27 Suppl 1:S1-9.

24. Lee YK. Comparison of CIELAB deltaE $\left({ }^{*}\right)$ and CIEDE2000 color-differences after polymerization and thermocycling of resin composites. Dent Mater 2005;21:678-82.

25. Xu BT, Zhang B, Kang Y, Wang YN, Li Q. Applicability of CIELAB/CIEDE2000 formula in visual color assessments of metal ceramic restorations. J Dent 2012;40 Suppl 1:e3-9.

26. de Alencar E Silva Leite ML, da Cunha Medeiros E Silva FD, Meireles SS, Duarte RM, Andrade AK. The effect of drinks on color stability and surface roughness of nanocomposites. Eur J Dent 2014;8:330-6.

27. Eliades T, Eliades G, Silikas N, Watts DC. In vitro degradation of polyurethane orthodontic elastomeric modules. J Oral Rehabil 2005;32:72-7 